\title{
Urogynecology in obstetrics: impact of pregnancy and delivery on pelvic floor disorders, a prospective longitudinal observational pilot study
}

\author{
Russalina Stroeder ${ }^{1}$ (D ) Julia Radosa ${ }^{1}$. Lea Clemens ${ }^{1}$. Christoph Gerlinger ${ }^{1}$. Gilda Schmidt ${ }^{1}$. \\ Panagiotis Sklavounos ${ }^{1}$ - Zoltan Takacs ${ }^{1}$ - Gabriele Meyberg-Solomayer ${ }^{1}$ - Erich-Franz Solomayer ${ }^{1} \cdot$ Amr Hamza $^{1,2}$
}

Received: 29 November 2020 / Accepted: 4 March 2021 / Published online: 22 March 2021

(c) The Author(s) 2021

\begin{abstract}
Purpose To assess changes in the pelvic floor anatomy that cause pelvic floor disorders (PFDs) in primigravidae during and after pregnancy and to evaluate their impact on women's quality of life (QoL).

Methods POP-Q and translabial ultrasound examination was performed in the third trimester and 3 months after delivery in a cohort of primigravidae with singleton pregnancy delivering in a tertiary center. Results were analyzed regarding mode of delivery and other pre- and peripartal factors. Two individualized detailed questionnaires were distributed at 3 months and at 12 months after childbirth to determinate QoL.

Results We recruited 45 women, of whom 17 delivered vaginally (VD), 11 received a vacuum extraction delivery (VE) and 17 a Cesarean section in labor (CS). When comparing third-trimester sonography to 3 months after delivery, bladder neck mobility increased significantly in each delivery group and hiatal area increased significantly in the VD group. A LAM avulsion was found in two women after VE. Connective tissue weakness $(p=0.0483)$ and fetal weight at birth $(p=0.0384)$ were identified as significant risk factors for the occurrence of PFDs in a multivariant regression analysis. Urinary incontinence was most common with $15 \%$ and $11 \%$ of cases at 3 , respectively, 12 months after delivery. $42 \%$ of women reported discomfort during sexual intercourse, 3 months after delivery and $24 \% 12$ months postpartum. Although $93 \%$ of women engage a midwife after delivery, only $56 \%$ participated in pelvic floor muscle training.

Conclusion Connective tissue weakness and high fetal weight at birth are important risk factors for the occurrence of PFDs. Nevertheless, more parturients should participate in postpartal care services to prevent future PFDs.
\end{abstract}

Keywords Pelvic floor disorders · POP-Q · Translabial ultrasound · Quality of life · Preventive treatment strategies

\section{Introduction}

Pelvic floor disorders (PFDs), including urinary incontinence (UI), anal incontinence (AI) and pelvic organ prolaps (POP), affect up to $30 \%$ of the adult female population [1-3]. The prevalence is likely to grow in the aging population, consequently causing an increase in health-care expenditures

Russalina Stroeder

russalina.stroeder@uks.eu

1 Department of Gynecology, Obstetrics and Reproductive Medicine, University Medical School of Saarland, Kirrberger Straße, 66421 Homburg, Saar, Germany

2 Department of Obstetrics and Prenatal Medicine, Kantonspital Baden, Im Ergel 1, 5400 Baden, Switzerland
$[4,5]$. Knowledge of the mechanisms leading to PFDs in later life offers the opportunity to initiate preventive treatment strategies. The etiology of PFDs is yet complex and multifactorial. Genetic predisposition, lifestyle factors, BMI, aging, pregnancy and delivery all play an important role [1, 3, 6-17]. During gestation, the weight gain and increase in uterine weight increases the intra-abdominal pressure. Therefore, ligamentous structures and pelvic floor muscles are overstretched [6]. The expanding retrovesical angle increases furthermore the BNM and results in UI [18]. Hormonal and mechanical changes during pregnancy also contribute to impairment of normal pelvic floor function [19]. This explains why Cesarean section (CS) is not entirely protective against development of PFDs [20]. Childbirth can furthermore result in myogenic, neurogenic damage and/or connective tissue damage. In most cases, these changes are 
reversible and the pelvic floor muscle function recovers during the first year after delivery [21, 22]. Pelvic floor changes appear to be irreversible in only $5-20 \%$ and then leading to PFDs in later life [20]. This collective may benefit from preventive treatment strategies (PTS), such as pelvic floor muscle training (PFMT), physiotherapy, pessar therapy, use of topical estrogen therapy, electrostimulation, etc. [23, 24] PFDs give rise to sexual disorders, which results in detrimental effects on women's quality of life (QoL) [25]. However, the physiopathology of PFDs is not fully established and longitudinal studies with objective quantitative data are rare [20].

Changes in pelvic floor anatomy such as: increased bladder neck mobility (BNM), stretching of the levator hiatus and injuries of the levator ani muscle (LAM avulsion) were already detected in previous studies [26-35]. The purpose of this study was to evaluate changes in pelvic floor biometry and function and its clinical implications in and after pregnancy using POP-Q, translabial ultrasound and questionnaires.

This should help to identify former primigravidae with high risk factors for occurrence of PFDs and help inform them about possible PTS.

\section{Methods}

The recruitment took place from May to October 2017. Our prospective longitudinal observational study included only primigravidae with uncomplicated singleton pregnancy planned for delivery in our tertiary center, who agreed to participate after signing the written informed consent. Exclusion criteria were only age $<18$ years, multigravidae and multiples.

45 out of 56 returned for follow-up 3 months after delivery. The study protocol was approved by the local Ethical Committee. On recruitment, we performed a vaginal examination, a POP-Q test and translabial 2D/3D ultrasound examination in the third trimester of pregnancy (34th-36th gestational week) and 3 months after delivery, as illustrated in Fig. 1.

Primary outcome parameters were anatomic changes of the pelvic floor as measured by ultrasound and clinical examination (bladder neck mobility, changes of the levator hiatus, occurrence of pelvic floor prolaps). Secondary outcomes were possible limitations in quality of life, occurrence of incontinence symptoms, physical activity, participation in pelvic floor muscle training and changes in sexual function.

Vaginal examination was performed in the lithotomy position. Genital descent was evaluated at rest and on Valsalva maneuver (VM) using the POP-Q grading system proposed by the International Continence Society [36].

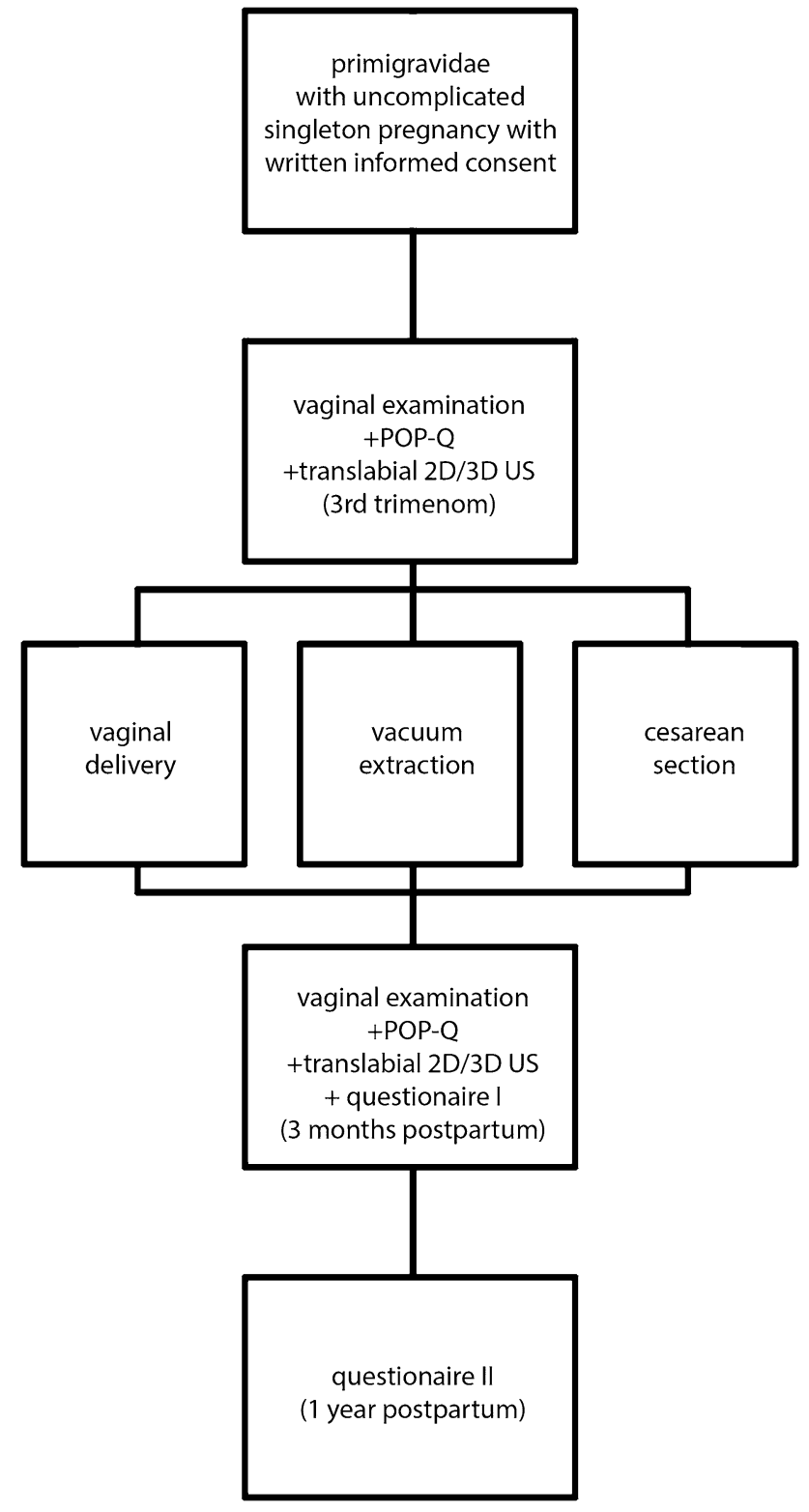

Fig. 1 Overview of study procedure

Translabial ultrasound examination was performed by one of two investigators (A.H. and R.S.) who had ultrasound experience for several years. A GE Voluson 730 ultrasound system (GE Healthcare, Hoevelaken, The Netherlands) with RAB 4-8 MHz curved array 3D/4D ultrasound transducer was used. The ultrasound transducer was covered sterile and placed vertically on the perineum in the sagittal plane with the participant in a supine position after micturition. Datasets were obtained at rest and on maximum VM.

The pelvic floor was initially visualized in B-mode to evaluate the BNM, which is strongly associated with the onset of UI $[32,37,38]$. To visualize the BNM, we measured the bladder neck descent and the retrovesical angle ( $($ ) 
at rest and on VM. The bladder neck descent was measured relatively to the inferior margin of the symphysis pubis as an immobile reference point as previously described by Dietz HP $[39,40]$. The retrovesical angle ( $ß$ ) was measured between the dorsal urethral axis and the axis of the floor of the bladder, as previously described by Green et al. [41]. The normal angle was defined as $90-100^{\circ}$ in non-pregnant women. It increases in women with UI [38, 42].

The levator hiatal dimensions were measured in the axial plane of least levator hiatal gap by 3D ultrasound, identified in the mid-sagittal image as the minimal distance between the posterior-inferior margin of the symphysis pubis and anorectal junction. We obtained the hiatal measurements using the rendering technique as described previously by Dietz $[34,43]$. The following measurements were collected at rest and on VM to estimate the contractility and distensibility of the levator hiatus: (1) anteroposterior diameter of the levator hiatus (LH-ap), (2) the levator hiatal transverse diameter (LH-rl) and (3) the area of the levator hiatus (LHarea), bordered by the pubovisceral muscle, symphysis pubis and the inferior pubic ramus. Ballooning of the levator hiatus was defined as a distension of the hiatal area $>25 \mathrm{~cm}^{2}$ which is associated with POP [44-46].

We also assessed LAM integrity. LAM avulsion was diagnosed if the distance between the center of the urethra and the LAM insertion (levator-urethra gap) was $>/=25 \mathrm{~mm}$. LAM avulsion is also associated with POP [44, 45, 47]. Offline analyses of the rendered volume datasets were performed.

Two individualized non-validated detailed questionnaires (appended in the attachment) were distributed at 3 months postpartum visit and 12 months after childbirth on postal way to assess QoL, occurrence of PFDs and women's behavior after childbirth (weight, breast feeding, postpartal engagement of a midwife, participation at pelvic floor muscle training or other specialized treatments, activity and sports).

The following clinical data and intrapartal parameters were received from the medical records database: (1) gestational age at childbirth, (2) delivery mode, (3) anesthesia, (4) induction of labor (IOL), (5) medication during labor, (6) length of the delivery periods, (7) fetal measurements, (8) perineal and other genital injuries.

Data base was edited in Microsoft Excel Mac 2011 (Redmond, USA) and anonymized before starting statistical assessment. Following the intention-to-treat principle all patients with available data were included in the analyses. Categorical variables were described using absolute and relative frequency counts whereas continuous variables were described using the number of observations, mean, and standard deviation. As a result of the low frequencies of UI, AI, and mixed incontinence the dichotomized variable incontinence (yes/no) was used as the dependent variable
Table 1 Patient characteristics

\begin{tabular}{ll}
\hline Characteristics & \\
\hline Age [years] & 31 (range 18-40) \\
Body mass index before pregnancy $\left[\mathrm{kg} / \mathrm{m}^{2}\right]$ & $25 \pm 5.1$ \\
Weight increase through pregnancy $[\mathrm{kg}]$ & $15 \pm 6.6$ \\
Connective tissue weakness & $23(51.1 \%)$ \\
Gestational diabetes & $6(13 \%)$ \\
\hline
\end{tabular}

Table 2 Peripartal parameters and fetal characteristics

\begin{tabular}{ll}
\hline Peripartal parameters & Number of participants \\
\hline Gestational age at delivery [weeks] & $40 \pm 1.6$ \\
Induction of labor & $18(40 \%)$ \\
Mode of delivery & $17(37.8 \%)$ \\
Vaginal delivery & $11(24.4 \%)$ \\
Vacuum assisted delivery & $17(37.8 \%)$ \\
Cesarean section in labor & $12(27 \%)$ \\
Peridural anesthesia & \\
Length of delivery period [min] & 208 \\
First stage of labor & 66 \\
Second stage of labor & 274 \\
Total & $18(40 \%)$ \\
Episiotomy & $4(9 \%)$ \\
III ${ }^{\circ}$ perineal tear & $3213($ range 2100-4200) \\
Fetal weight [g] & $34($ range 31-37.5) \\
Fetal head circumference [cm] &
\end{tabular}

in the logistic regressions. A stepwise selection procedure with limits 0.1 for inclusion and/or exclusion of variables was used. Owing to the explorative nature of the study, a comparison-wise two-sided significance level of 5\% was applied. The statistical analyses were carried out using SAS version 9.4 software (SAS Inc. Cary, NC, USA).

\section{Results}

We recruited 56 women, of whom $45(80.4 \%)$ completed the study. 11 women were excluded from the study due to refusal of further participation $(n=8)$, delivery in another hospital $(n=2)$ and intrauterine fetal death $(n=1)$. Patients' characteristics are displayed in Table 1 . Table 2 shows peripartal parameters and fetal characteristics. The most frequent indication for induction of labor was post-term pregnancy. The most frequent indication for CS and VE was pathological fetal monitoring during first, respectively, second-stage of labor.

Differences in pelvic floor function before and after childbirth depending on different delivery mode are presented in Table 3. Comparing third-trimester sonography to 3 months 
Table 3 Quantitative parameters assessed in translabial sonography during pregnancy and after different modes of delivery

\begin{tabular}{|c|c|c|c|c|c|c|c|}
\hline & \multirow{2}{*}{$\begin{array}{l}\text { During pregnancy (34- } \\
\text { 36th week) } n=45 \\
\text { mean } \pm \mathrm{SD}\end{array}$} & \multicolumn{2}{|c|}{ Spontaneous delivery $n=17$} & \multicolumn{2}{|c|}{ Vacuum extraction $n=11$} & \multicolumn{2}{|c|}{ Cesarean section $n=17$} \\
\hline & & mean $\pm \mathrm{SD}$ & $p$ value & mean $\pm \mathrm{SD}$ & $p$ value & mean $\pm \mathrm{SD}$ & $p$ value \\
\hline $\mathrm{BNM}[\mathrm{cm}]$ & 0.2 & $1.04 \pm 0.26$ & $<0.0001 *$ & $0.86 \pm 0.32$ & $.0072 *$ & $1.08 \pm 0.33$ & $<0.0001 *$ \\
\hline Retrovesical angle $\left[{ }^{\circ}\right]$ & $132.6 \pm 9.74$ & $132.08 \pm 14.53$ & 0.76 & $133.64 \pm 7.45$ & .41 & $122.06 \pm 18.55$ & 0.51 \\
\hline $\begin{array}{l}\text { Hiatal area } \\
\text { on } \mathrm{VM}\left[\mathrm{cm}^{2}\right]\end{array}$ & 13.37 & $16.81 \pm 4.67$ & $0.0117 *$ & $13.35 \pm 1.97$ & .49 & $13.55 \pm 2.86$ & 0.66 \\
\hline LAM avulsion & 0 & 0 & & 2 & & 0 & \\
\hline Ballooning & 0 & 2 & & 0 & & 0 & \\
\hline
\end{tabular}

Hiatal area was significantly smaller after VE $(p$ value $=0.04)$ and CS $(p$ value $=0.03)$ than after spontaneous delivery

$B N M$ bladder neck mobility, $L A M$ levator ani muscle

$p$ value (paired $t$ tests comparing values during pregnancy and post-partum, significant $p$ value $(<0.05)$ marked with an asterisk)

postpartum, BNM increased significantly on VM from 2 to $10 \mathrm{~mm}$ in each delivery group. The retrovesical angle decreased from $132.6 \pm 9.74^{\circ}$ to $128.3 \pm 15.6^{\circ}$, which was not significant and the hiatal area increased on VM from mean $13.37-14.53 \mathrm{~cm}^{2}$. The increase of the hiatal area was only significant in the VD group in the paired t test. Ballooning of the hiatal area was found in two women after VD. A LAM avulsion was diagnosed in two women 3 months after VE delivery.

POP-Q test showed an anterior stage 1 in four women in the third trimester and in seven cases 3 months after delivery. We diagnosed three cases of posterior POP-Q stage 1 in the third trimester and five cases 3 months after delivery.

Among pre- and peripartal parameters connective tissue weakness as existence of cellulitis or striae $(p=0.0483)$ and fetal weight at birth $(p=0.0384)$ were identified as significant risk factors for the occurrence of PFDs in a multivariant regression analysis.

$12(26.7 \%)$ women reported UI during pregnancy. UI was reported 3 months and 12 months postpartum in seven and five, AI in three and two and a combined urinary and anal incontinence in seven and one woman, respectively. Seven out of 11 (64\%) participants, who underwent VE showed symptoms 3 months postpartum, although there was no significant association between mode of delivery and the occurrence of PFDs.

$19(42 \%)$ and $11(24 \%)$ women reported discomfort during sexual intercourse 3 and 12 months after delivery, respectively. Dyspareunia was stated by $12(27 \%)$ and 7 (16\%) cases 3 and 12 months postpartum, respectively. 17 $(38 \%)$ stated no changes during intercourse while 9 participants $(20 \%)$ had no intercourse throughout the survey. In still $11(24 \%)$ of the participants symptoms of discomfort during sexual intercourse remained 12 months postpartum.

Although $93 \%$ of women are followed up by a midwife after delivery, only 56\% participated in PFMT and $35 \%$ of women with incontinence symptoms used additional specialized treatments as physiotherapy or electrostimulation.

\section{Discussion}

To our knowledge, we are one of few studies evaluating the occurrence of PFDs in a prospective longitudinal setting (during pregnancy and after childbirth) using a combination of pelvic floor examination, POP-Q and translabial 2D and 3D ultrasound. Furthermore, we investigate the impact of changes in pelvic floor on women's QoL with the help of individualized questionnaires. This study may offer a better understanding of the pelvic floor function in context of gestation and delivery and its clinical relevance.

Most studies applied only one method for evaluating pelvic organs changes, e.g. POP-Q [22, 48] or perineal ultrasound $[30,49]$ with or without clinical correlation through a questionnaire. To our knowledge, only Jundt et al. [27] used a similar setup combining a questionnaire with POP-Q and perineal ultrasound in primiparous women between 32 and 37 weeks' and 6 months postpartum.

Only few prospective studies with longitudinal follow-up using questionnaires provide information on all aspects of PFDs and/or include antenatal assessment. Macarthur et al. [50] e.g., only evaluated AI in context with childbirth and Van Brummen et al. [51] focused on UI after delivery.

Our study population consists of women with an advanced age of first gestation, a high BMI and a high percentage of instrumental deliveries (24\%) or CS $(38 \%)$, which is representative in our university hospital. Knowing this, the findings of this study cannot be generalized due to possible demographic differences.

The observational period chosen in our study extended from the third trimester to one year after delivery. Clinical measurements and a questionnaire were applied in third trimester and 3 months postpartum and only a questionnaire 
after 1 year with the aim to avoid poor follow-up rates. Our drop-out rate was $19.6 \%$ compared to Elenskaia et al. [48] e.g., who performed a similar study with a drop-out rate of $46.7 \%$.

Our first exam was performed in third trimester. Therefore our results did not include early pregnancy patients as presented by Dietz et al. [30], who performed a prospective observational study in nulliparous women starting at 6-18 pregnancy weeks.

To avoid using several different validated questionnaires to cover the questions of interest, we decided to use two individualized none-validated questionnaires in contrast to other authors [48]. In addition, Zuchelo et al. [52] postulated that validated questionnaires are developed for women with incontinence and are not suitable for the postpartum period. They recommended new designed questionnaires to improve early and specific approach for this period of life. We used a self-administered questionnaire to avoid physician dependent bias.

Comparing third trimester 2D sonography to 3 months postpartum, BNM increased significantly on VM in all delivery groups. This was idem to the findings of Peschers et al. [53] who compared primiparae to nulligravid volunteers. They reported an increase in BNM in most women delivering vaginally. Increased BNM is associated with occurrence of UI [27, 49]. UI was most frequently reported among the PFDs with $31 \%$ of cases, $42.9 \%$ of whom already occurring during pregnancy.

In the VD group the hiatal area increased significantly on $\mathrm{VM}$ and $4 \%$ of women even present a ballooning in the 3D sonography. $4 \%$ of women had a LAM avulsion after VE. Other study groups report higher incidences. Shek et al. [54] e.g., detected $13 \%$ LAM avulsion and $28.5 \%$ ballooning in 367 primiparous women undergoing perineal ultrasound 2 , respectively. 6 months postpartum.

The prevalence of POP was low in our collective with no cases of high-grade pelvic organ changes during pregnancy and after delivery. A prospective Norwegian study [22] of 300 nulliparous women also reported a low prevalence for POP during pregnancy from 0 to $10 \%$ and a recovery to baseline of all POP-Q points except the cervix at 12 months postpartum.

Connective tissue weakness and fetal weight at birth were identified as significant risk factors for PFDs in a multivariant regression analysis. This is comparable to the findings from other study groups. Miedel et al. [55] also reported about markers suggestive for congenital susceptibility (family history and conditions suggestive for weakened connective tissue) and non-obstetrical strain on the pelvic floor (overweight/obesity, heavy lifting and constipation). This implies an individual predisposition towards PFDs. Keane et al. compared premenopausal nulliparous women with urodynamically proven genuine stress incontinence with healthy controls and showed a defect in their connective tissue responsible for the UI [56]. In accordance to our results, Gyhagen et al. [16] found a significant correlation between high birth weight, LAM avulsion and genital descensus.

Conventionally known risk factors [16, 57], e.g., maternal age, obesity, breastfeeding, length of the second delivery period, fetal head circumference, perineal rupture were not found significant in our study due to small number of cases.

Our results suggest that VE may be associated with more UI and/or AI occurrence, since $64 \%$ of women were symptomatic after VE. Jundt et al. [27] already showed a relation between increase of BNM and VE.

From the questionnaires we concluded, that $27 \%$ of women stated dyspareunia 3 months postpartum and $16 \%$ 1 year after childbirth. This is comparable to the findings of Connolly et al. [58] reporting dyspareunia in $17 \%$ after childbirth.

There were few findings of concern in the questionnaires. Although 93\% of women engage a midwife after delivery, only $56 \%$ participated in PFMT. Only $35 \%$ of women with incontinence symptoms used additional specialized treatments. Although several randomized controlled trials [23, 24] have clearly shown that intensive and supervised PFMT with/without biofeedback is effective for providing PFDs. A possible explanation might be the lack of time due to motherhood duties or the limited symptoms resulting from pelvic floor changes at this time. Informing women properly about PFD development and options of PTS, appears to be necessary to prevent PFDs in later life time and reduce the costs of managing future cases of incontinence.

The major limitation in our study was the number of cases, which was too low to establish statistically valid outcomes. We, therefore, classify our study as a pilot study. Further investigations are needed to verify our findings. We plan to do so in a multicenter fashion.

\section{Conclusion}

Both, pregnancy and delivery have an effect on changes of the female pelvic floor. BNM increases after delivery when compared to pregnancy. Connective tissue weakness and high fetal weight at birth are identified as significant risk factors for the occurrence of PFDs in our study population. Although most of the parturient engage a postpartal midwifery care, yet only half of the patients participate in PFMT and only one third of women with incontinence symptoms used indicated specialized treatments. The participation rate in postpartal care services should be improved to implement an effective prevention for future PFDs.

Supplementary Information The online version contains supplementary material available at https://doi.org/10.1007/s00404-021-06022-w. 
Author contributions RS: project development, data collection, manuscript writing. JR: manuscript editing. LC: data collection and management. CG: data analysis. GS: project development. PS: urogynecological support. ZT: sonographical support. GM-S: manuscript editing. EFS: project development, manuscript editing. AH: project development, data collection, manuscript editing.

Funding Open Access funding enabled and organized by Projekt DEAL

\section{Declarations}

Conflict of interest All authors have no conflicts of interest to disclose.

Ethical approval Saarland Ethical Committee number 47/17.

Consent to participate Written informed consent was obtained from all participants.

Consent for publication Participants consented to publication in a scientific journal.

Open Access This article is licensed under a Creative Commons Attribution 4.0 International License, which permits use, sharing, adaptation, distribution and reproduction in any medium or format, as long as you give appropriate credit to the original author(s) and the source, provide a link to the Creative Commons licence, and indicate if changes were made. The images or other third party material in this article are included in the article's Creative Commons licence, unless indicated otherwise in a credit line to the material. If material is not included in the article's Creative Commons licence and your intended use is not permitted by statutory regulation or exceeds the permitted use, you will need to obtain permission directly from the copyright holder. To view a copy of this licence, visit http://creativecommons.org/licenses/by/4.0/.

\section{References}

1. Nygaard I, Barber MD, Burgio KL et al (2008) Prevalence of symptomatic pelvic floor disorders in US women. JAMA 300:1311-1316. https://doi.org/10.1001/jama.300.11.1311

2. Barlow DH, Samsioe G, van Geelen JM (1997) A study of European womens' experience of the problems of urogenital ageing and its management. Maturitas 27:239-247. https://doi.org/10. 1016/s0378-5122(97)00047-9

3. Rortveit G, Brown JS, Thom DH et al (2007) Symptomatic pelvic organ prolapse: prevalence and risk factors in a population-based, racially diverse cohort. Obstet Gynecol 109:1396-1403. https:// doi.org/10.1097/01.AOG.0000263469.68106.90

4. Subak LL, Waetjen LE, van den Eeden S et al (2001) Cost of pelvic organ prolapse surgery in the United States. Obstet Gynecol 98:646-651. https://doi.org/10.1016/s0029-7844(01)01472-7

5. Sung VW, Washington B, Raker CA (2010) Costs of ambulatory care related to female pelvic floor disorders in the United States. Am J Obstet Gynecol 202:483.e1-4. https://doi.org/10.1016/j. ajog.2010.01.015

6. Lukacz ES, Lawrence JM, Contreras R et al (2006) Parity, mode of delivery, and pelvic floor disorders. Obstet Gynecol 107:12531260. https://doi.org/10.1097/01.AOG.0000218096.54169.34

7. Memon H, Handa VL (2012) Pelvic floor disorders following vaginal or cesarean delivery. Curr Opin Obstet Gynecol 24:349-354. https://doi.org/10.1097/GCO.0b013e328357628b
8. Jelovsek JE, Maher C, Barber MD (2007) Pelvic organ prolapse. Lancet (London, England) 369:1027-1038. https://doi.org/10. 1016/S0140-6736(07)60462-0

9. Slieker-ten Hove MCP, Pool-Goudzwaard AL, Eijkemans MJC et al (2009) Symptomatic pelvic organ prolapse and possible risk factors in a general population. Am J Obstet Gynecol 200:184. e1-7. https://doi.org/10.1016/j.ajog.2008.08.070

10. Foldspang A, Mommsen S, Djurhuus JC (1999) Prevalent urinary incontinence as a correlate of pregnancy, vaginal childbirth, and obstetric techniques. Am J Public Health 89:209-212. https://doi. org/10.2105/ajph.89.2.209

11. Mant J, Painter R, Vessey M (1997) Epidemiology of genital prolapse: observations from the Oxford Family Planning Association Study. Br J Obstet Gynaecol 104:579-585. https://doi.org/ 10.1111/j.1471-0528.1997.tb11536.x

12. MacLennan AH, Taylor AW, Wilson DH, Wilson D (2000) The prevalence of pelvic floor disorders and their relationship to gender, age, parity and mode of delivery. BJOG 107:1460-1470. https://doi.org/10.1111/j.1471-0528.2000.tb11669.x

13. Carley ME, Turner RJ, Scott DE, Alexander JM (1999) Obstetric history in women with surgically corrected adult urinary incontinence or pelvic organ prolapse. J Am Assoc Gynecol Laparosc 6:85-89. https://doi.org/10.1016/s1074-3804(99) 80047-4

14. McLennan MT, Harris JK, Kariuki B, Meyer S (2008) Family history as a risk factor for pelvic organ prolapse. Int Urogynecol J Pelvic Floor Dysfunct 19:1063-1069. https://doi.org/10.1007/ s00192-008-0591-1

15. Lince SL, van Kempen LC, Vierhout ME, Kluivers KB (2012) A systematic review of clinical studies on hereditary factors in pelvic organ prolapse. Int Urogynecol J 23:1327-1336. https:// doi.org/10.1007/s00192-012-1704-4

16. Gyhagen M, Bullarbo M, Nielsen TF, Milsom I (2013) Prevalence and risk factors for pelvic organ prolapse 20 years after childbirth: a national cohort study in singleton primiparae after vaginal or caesarean delivery. BJOG 120:152-160. https://doi. org/10.1111/1471-0528.12020

17. Vergeldt TFM, Weemhoff M, IntHout J, Kluivers KB (2015) Risk factors for pelvic organ prolapse and its recurrence: a systematic review. Int Urogynecol J 26:1559-1573. https://doi.org/ 10.1007/s00192-015-2695-8

18. Herbert J (2009) Pregnancy and childbirth: the effects on pelvic floor muscles. Nurs Times 105:38-41

19. Van Geelen JM, Doesburg WH, Thomas CM, Martin CB (1981) Urodynamic studies in the normal menstrual cycle: the relationship between hormonal changes during the menstrual cycle and the urethral pressure profile. Am J Obstet Gynecol 141:384392. https://doi.org/10.1016/0002-9378(81)90599-8

20. Van Geelen H, Ostergard D, Sand P (2018) A review of the impact of pregnancy and childbirth on pelvic floor function as assessed by objective measurement techniques. Int Urogynecol J 29:327-338. https://doi.org/10.1007/s00192-017-3540-z

21. Staer-Jensen J, Siafarikas F, Hilde G et al (2015) Postpartum recovery of levator hiatus and bladder neck mobility in relation to pregnancy. Obstet Gynecol 125:531-539. https://doi.org/10. 1097/AOG.0000000000000645

22. Reimers C, Staer-Jensen J, Siafarikas F et al (2016) Change in pelvic organ support during pregnancy and the first year postpartum: a longitudinal study. BJOG 123:821-829. https://doi. org/10.1111/1471-0528.13432

23. Boyle R, Hay-Smith EJC, Cody JD, Mørkved S (2014) Pelvic floor muscle training for prevention and treatment of urinary and fecal incontinence in antenatal and postnatal women: a short version Cochrane review. Neurourol Urodyn 33:269-276. https://doi.org/10.1002/nau.22402 
24. Pelaez M, Gonzalez-Cerron S, Montejo R, Barakat R (2014) Pelvic floor muscle training included in a pregnancy exercise program is effective in primary prevention of urinary incontinence: a randomized controlled trial. Neurourol Urodyn 33:6771. https://doi.org/10.1002/nau.22381

25. Abdool Z, Thakar R, Sultan AH (2009) Postpartum female sexual function. Eur J Obstet Gynecol Reprod Biol 145:133-137. https://doi.org/10.1016/j.ejogrb.2009.04.014

26. Dietz HP, Eldridge A, Grace M, Clarke B (2004) Does pregnancy affect pelvic organ mobility? Aust N Z J Obstet Gynaecol 44:517-520. https://doi.org/10.1111/j.1479-828X.2004.00301.x

27. Jundt K, Scheer I, Schiess1 B et al (2010) Incontinence, bladder neck mobility, and sphincter ruptures in primiparous women. Eur J Med Res 15:246-252. https://doi.org/10.1186/ 2047-783x-15-6-246

28. Shek KL, Dietz HP, Kirby A (2010) The effect of childbirth on urethral mobility: a prospective observational study. J Urol 184:629-634. https://doi.org/10.1016/j.juro.2010.03.135

29. Dietz HP (2004) Levator function before and after childbirth. Aust N Z J Obstet Gynaecol 44:19-23. https://doi.org/10.1111/j.1479828X.2004.00140.x

30. Dietz HP, Bennett MJ (2003) The effect of childbirth on pelvic organ mobility. Obstet Gynecol 102:223-228. https://doi.org/10. 1016/s0029-7844(03)00476-9

31. Wijma J, Potters AEW, de Wolf BTHM et al (2003) Anatomical and functional changes in the lower urinary tract following spontaneous vaginal delivery. BJOG 110:658-663

32. Shek KL, Kruger J, Dietz HP (2012) The effect of pregnancy on hiatal dimensions and urethral mobility: an observational study. Int Urogynecol J 23:1561-1567. https://doi.org/10.1007/ s00192-012-1795-y

33. Shek KL, Dietz HP (2009) The effect of childbirth on hiatal dimensions. Obstet Gynecol 113:1272-1278. https://doi.org/10. 1097/AOG.0b013e3181a5ef23

34. Dietz HP, Shek C, Clarke B (2005) Biometry of the pubovisceral muscle and levator hiatus by three-dimensional pelvic floor ultrasound. Ultrasound Obstet Gynecol 25:580-585. https://doi.org/ 10.1002/uog.1899

35. Dietz HP, Lanzarone V (2005) Levator trauma after vaginal delivery. Obstet Gynecol 106:707-712. https://doi.org/10.1097/ 01.AOG.0000178779.62181.01

36. Bump RC, Mattiasson A, Bø K et al (1996) The standardization of terminology of female pelvic organ prolapse and pelvic floor dysfunction. Am J Obstet Gynecol 175:10-17. https://doi.org/10. 1016/S0002-9378(96)70243-0

37. Dietz H, Clarke B, Vancaillie T (2002) Vaginal childbirth and bladder neck mobility. Aust New Zeal J Obstet Gynaecol 42:522_ 525. https://doi.org/10.1111/j.0004-8666.2002.00522.x

38. Pregazzi R, Sartore A, Bortoli P et al (2002) Perineal ultrasound evaluation of urethral angle and bladder neck mobility in women with stress urinary incontinence. BJOG An Int J Obstet Gynaecol 109:821-827. https://doi.org/10.1111/j.1471-0528.2002.01163.x

39. Dietz HP (1989) Perineal Scan: eine neue Untersuchungsmethode in der Gynaekologie und Geburtshilfe. University of Heidelberg Medical School, Heidelberg

40. Dietz HP (2004) Ultrasound imaging of the pelvic floor. Part I: two-dimensional aspects. Ultrasound Obstet Gynecol 23:80-92. https://doi.org/10.1002/uog.939

41. Green TH (1975) Urinary stress incontinence: differential diagnosis, pathophysiology, and management. Am J Obstet Gynecol 122:368-400. https://doi.org/10.1016/0002-9378(75)90186-6

42. Alper T, Çetinkaya M, Okutgen S et al (2001) Evaluation of urethrovesical angle by ultrasound in women with and without urinary stress incontinence. Int Urogynecol J 12:308-311. https:// doi.org/10.1007/s001920170031
43. Dietz HP (2004) Ultrasound imaging of the pelvic floor. Part II: three-dimensional or volume imaging. Ultrasound Obstet Gynecol 23:615-625. https://doi.org/10.1002/uog.1072

44. Notten KJB, Vergeldt TFM, van Kuijk SMJ et al (2017) Diagnostic accuracy and clinical implications of translabial ultrasound for the assessment of levator ani defects and levator ani biometry in women with pelvic organ prolapse. Female Pelvic Med Reconstr Surg 23:420-428. https://doi.org/10.1097/SPV.0000000000 000402

45. Dietz HP (2019) Ultrasound in the assessment of pelvic organ prolapse. Best Pract Res Clin Obstet Gynaecol 54:12-30. https:// doi.org/10.1016/j.bpobgyn.2018.06.006

46. Dietz HP, Shek C, De Leon J, Steensma AB (2008) Ballooning of the levator hiatus. Ultrasound Obstet Gynecol 31:676-680. https:// doi.org/10.1002/uog.5355

47. DeLancey JOL, Morgan DM, Fenner DE et al (2007) Comparison of levator ani muscle defects and function in women with and without pelvic organ prolapse. Obstet Gynecol 109:295-302. https://doi.org/10.1097/01.AOG.0000250901.57095.ba

48. Elenskaia K, Thakar R, Sultan AH et al (2013) Effect of childbirth on pelvic organ support and quality of life: a longitudinal cohort study. Int Urogynecol J 24:927-937. https://doi.org/10.1007/ s00192-012-1932-7

49. King JK, Freeman RM (1998) Is antenatal bladder neck mobility a risk factor for postpartum stress incontinence? $\mathrm{Br} \mathrm{J}$ Obstet Gynaecol 105:1300-1307. https://doi.org/10.1111/j.1471-0528. 1998.tb10009.x

50. Macarthur C, Glazener C, Lancashire R et al (2005) Faecal incontinence and mode of first and subsequent delivery: a six-year longitudinal study. BJOG 112:1075-1082. https://doi.org/10.1111/j. 1471-0528.2005.00721.x

51. van Brummen HJ, Bruinse HW, van de Pol G et al (2007) The effect of vaginal and cesarean delivery on lower urinary tract symptoms: what makes the difference? Int Urogynecol J Pelvic Floor Dysfunct 18:133-139. https://doi.org/10.1007/ s00192-006-0119-5

52. Zuchelo LTS, Bezerra IMP, Da Silva ATM et al (2018) Questionnaires to evaluate pelvic floor dysfunction in the postpartum period: a systematic review. Int J Womens Health 10:409-424. https://doi.org/10.2147/IJWH.S164266

53. Peschers UM, Fanger G, Schaer GN et al (2001) Bladder neck mobility in continent nulliparous women. BJOG An Int J Obstet Gynaecol 108:320-324. https://doi.org/10.1111/j.1471-0528. 2001.00066.x

54. Shek K, Dietz H (2010) Intrapartum risk factors for levator trauma. BJOG An Int J Obstet Gynaecol 117:1485-1492. https:// doi.org/10.1111/j.1471-0528.2010.02704.x

55. Miedel A, Tegerstedt G, Maehle-Schmidt M et al (2009) Nonobstetric risk factors for symptomatic pelvic organ prolapse. Obstet Gynecol 113:1089-1097. https://doi.org/10.1097/AOG.0b013 e3181a11a85

56. Keane DP, Sims TJ, Abrams P, Bailey AJ (1997) Analysis of collagen status in premenopausal nulliparous women with genuine stress incontinence. BJOG An Int J Obstet Gynaecol 104:994998. https://doi.org/10.1111/j.1471-0528.1997.tb12055.x

57. Valsky DV, Lipschuetz M, Bord A et al (2009) Fetal head circumference and length of second stage of labor are risk factors for levator ani muscle injury, diagnosed by 3-dimensional transperineal ultrasound in primiparous women. Am J Obstet Gynecol 201:91.e1-7. https://doi.org/10.1016/j.ajog.2009.03.028

58. Connolly A, Thorp J, Pahel L (2005) Effects of pregnancy and childbirth on postpartum sexual function: a longitudinal prospective study. Int Urogynecol J Pelvic Floor Dysfunct 16:263-267. https://doi.org/10.1007/s00192-005-1293-6 
Publisher's Note Springer Nature remains neutral with regard to jurisdictional claims in published maps and institutional affiliations. 